\section{Modified laser DCR for paediatric nasolacrimal duct obstruction}

\begin{abstract}
Aims To evaluate the efficacy, safety, and long-term outcome of modified laser dacryocystorhinostomy (DCR) for primary nasolacrimal duct obstruction, unresponsive to probing.

Methods Retrospective, noncomparative case-note review of all paediatric cases operated between September 2000 and November 2003.

Procedure A fibre optic light, inserted through the canaliculi into the lacrimal sac was visualized endonasally. Nasal mucosa was incised using a keratome and a bony ostium was created with the Holmium : YAG laser. Bicanalicular silicone tubes were inserted.

Results Five children with a mean follow-up of 25.6 months (range 21-48 months) and a mean age of 7 years were reviewed. Silicone tubes were used in four patients and were removed at a mean 6.5 months (range 3-9 months). One patient developed a mucocele 6 months after the procedure requiring excision of the membrane covering the ostium. There were no other immediate or late postoperative complications. Complete cure of symptoms was achieved in all patients and was maintained at final

follow up.

Conclusion Modified paediatric laser DCR appears to be an encouraging technique for primary nasolacrimal duct obstruction unresponsive to probing. This may be attributable to the modification of excision of mucous membrane, which may prevent regrowth.
\end{abstract}

Eye (2006) 20, 347-350. doi:10.1038/sj.eye.6701886; published online 22 April 2005

Keywords: paediatric DCR; NLD block; failed probing; laser DCR
A Choudhary ${ }^{1}$ JAJ Deans ${ }^{2}$ and BJ Moriarty ${ }^{1}$

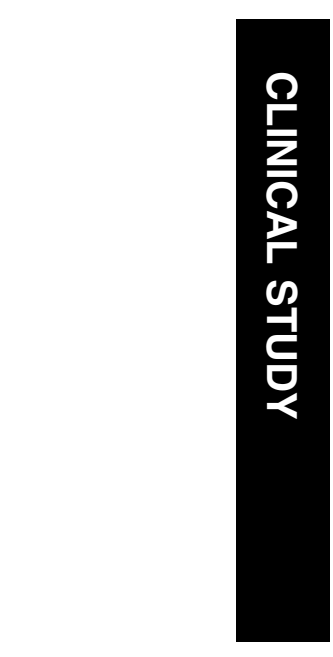

Introduction

The management of congenital nasolacrimal duct (NLD) obstruction following failed probing is controversial. Treatment options include repeat probing, stent intubation, and dacryocystorhinostomy (DCR). ${ }^{1}$ External DCR is a useful technique with success rates between 77 and $96 \%^{2-6}$ but carries the risk of blood loss, scarring, wound infection, and requires hypotensive anaesthesia.

These complications can be overcome by the endoscopic endonasal approach ${ }^{7}$ and there are two case-reports describing its use in children. ${ }^{8,9}$ The benefits of endonasal laser DCR are well established in adults with success rates between 63 and $97 \% .{ }^{10-16}$ Its role in children is yet to be evaluated and to date there has been only one case-series using the KTP laser with $0 \%$ success. ${ }^{17}$

We describe our experience with the Holmium: YAG laser using a modified technique in these cases with promising results. Our aims were to evaluate the efficacy, safety, and long-term outcome of this technique in children.

\section{Materials and methods}

Case notes for all paediatric patients undergoing laser DCR at Leighton Hospital, UK for primary NLD block between September 2000 and November 2003 were reviewed. All patients had failed at least one probing. Parameters noted were age, sex, previous and subsequent procedures, symptoms at presentation, and each follow-up, time for tube removal, complications and follow-up. If possible, patients were contacted by phone to enquire about their symptoms after final follow-up.

All procedures were performed as a combined procedure by an Ophthalmologist (BJM) and Otolaryngologist (JAJD).
${ }^{1}$ Department of Ophthalmology, Leighton Hospital, Crewe, Cheshire UK

${ }^{2}$ Department of Otolaryngology, Leighton Hospital, Crewe, Cheshire, UK

Correspondence:

A Choudhary, Unit of Ophthalmology, Department of Medicine, UCD, Duncan Building, University of Liverpool, Daulby Street, Liverpool L69 3GA, UK

Tel: +44 1517064283 ;

Fax: + 441517065934

E-mail: a.choudhary@

liv.ac.uk or

anshoo_choudhary@

hotmail.com

Received: 15 October 2004 Accepted: 22 February 2005 Published online: 22 April 2005 
Postoperative visits were at $2-4$ weeks by the

Ophthalmologist and at 3 months by the

Otolaryngologist.

Success was symptom based and defined as resolution of symptoms of epiphora as reported by parents and assessed clinically.

\section{Technique}

All cases were performed under general anaesthesia. The nose was prepared with $5 \%$ cocaine (calculated for weight) and the nasal mucosa was injected with $2 \%$ lignocaine with 1:80000 adrenaline for haemostasis. A light probe was passed through the lower or upper canaliculus as far down into the lacrimal sac as possible and visualized endonasally using a $0^{\circ}$ rigid fibre optic endoscope coupled to a video camera and display unit. Using a keratome a 3-4 $\mathrm{mm}$ area of the nasal mucosa was excised over the area of maximum brightness (which corresponds to the inferior end of the sac where the overlying bone is thinnest). The Holmium : YAG $2100 \mathrm{~nm}$ laser was then used to ablate and vaporize the lacrimal bone and medial wall of the lacrimal sac to create a rhinostomy approximately $5 \mathrm{~mm}$ in diameter. The settings were $1 \mathrm{~J} \times 10 \mathrm{~Hz}$. O'Donoghue tubes were inserted through the canaliculi and secured in the nasal cavity using a Watzke's sleeve and knotting.

Postoperative management included nasal and topical steroids for 6 weeks. Oral antibiotics were not used either before or after surgery. Tubes were left for at least 3 months and thereafter removed as an outpatient procedure.

\section{Results}

Five eyes of five children with a mean age of 7 years (range 4-9 years) and a mean duration of symptoms of
4.6 years (range 3-9 years) underwent laser DCR for primary congenital nasolacrimal duct block. The indication for surgery was persistent epiphora following one to two failed probings after the age of 12 months. Mean follow-up was 25.6 months (range 21-38 months). Patient demographics were as detailed in Table 1. Probing had originally relieved the block in patients 1, 3, and 5. Silicone tubes were used in four patients and removed at a mean 6.5 months (range 3-9 months).

All ostia were patent at 3 months. Apart from patient 1 who had a previous history of acute dacryocystitis and developed a mucocele postoperatively, there were no other early or late complications.

At final follow-up all patients were asymptomatic but for patient 5 who noticed slight epiphora in windy weather.

\section{Discussion}

Treatment options for congenital NLD block following failed probing include repeat probing with or without inferior turbinate infracture, closed stent intubation and DCR. ${ }^{1}$ There is as yet no consensus on the optimum treatment.

Success of probing decreases exponentially with increasing number and age. ${ }^{1,4}$ Inferior turbinate infracture is not routinely practised as it carries a risk of haemorrhage and formation of adhesions and synechiae. ${ }^{17}$ Most authors favour intubation ${ }^{1,17}$ before attempting DCR, which can cause punctual and canalicular damage, impairing the prognosis of subsequent surgery. We tend to repeat probing twice before proceeding to a DCR.

There are a few reports on paediatric DCR mainly external $^{2-6}$ with $77 \% \%^{5}-96 \% \%^{2,3}$ success. Although considered the gold standard, external DCR has several

Table 1 Patient demographics, symptoms, previous and subsequent procedures, complications, and follow-up

\begin{tabular}{|c|c|c|c|c|c|}
\hline Patient & $\begin{array}{l}\text { Age } \\
\text { (years) }\end{array}$ & $\begin{array}{l}\text { Follow-up } \\
\text { (months) }\end{array}$ & Complications and further intervention & Symptoms & Tubes removed (months) \\
\hline 1 & 9 & 21 & $\begin{array}{l}\text { Mucocele } 6 \text { months } \\
\text { postop-excision of nasal mucosa } \\
\text { covering ostium but no further laser }\end{array}$ & No epiphora & 3 \\
\hline 2 & 4 & 21 & Nil & No epiphora & No tubes (punctual fibrosis) \\
\hline 3 & 9 & 24 & Nil & No epiphora & 8 \\
\hline 4 & 4 & 38 & $\begin{array}{l}\text { Granulation tissue at lower ostium } \\
\text { on the first postoperative visit }\end{array}$ & $\begin{array}{l}\text { Slight } \\
\text { epiphora-relieved } \\
\text { after tube removal }\end{array}$ & 9 \\
\hline 5 & 9 & 24 & Nil & $\begin{array}{l}\text { Occasional } \\
\text { epiphora }\end{array}$ & 6 \\
\hline
\end{tabular}


disadvantages and limitations such as scarring, wound infection, blood loss, requirement of hypotensive anaesthesia, and potential injury to the medial canthal structures, ${ }^{7}$ which are accentuated in children. Wound infection is reported in 6.9-8\%, 3,4 blood loss in $1.25 \%^{4}$ and cellulitis in $2 \%^{2}$ in paediatric DCR.

The endonasal approach has obviated most of these disadvantages. It offers minimally invasive surgery with no scar, less disruption of the medial canthal anatomy and lacrimal pump function, the ability to concurrently address nasal abnormalities and decreased operative time, intraoperative haemorrhage, and postoperative morbidity. ${ }^{7}$ If subsequent external DCR is required there is sufficient untouched lacrimal sac and nasal mucosa as the ostium is in the middle or lower part of sac. ${ }^{11}$ Endonasal DCR can be technically challenging in children due to the small anatomical dimensions and potential trauma from the otological drill. Its experience in children is limited to two case-reports with success rates between 88 and 100\%. ${ }^{8,9}$ These problems can be overcome by laser DCR, which is relatively atraumatic with good manoeuvrability and haemostasis though at a cost of lower success rates. ${ }^{11,12}$ Its role in paediatric cases is yet to be evaluated and to our knowledge there has been only one case-series to date with $0 \%$ success. ${ }^{17}$

One of the major advantages of endonasal laser DCR is the reduced operating time. The average time taken for surgery was $23 \mathrm{~min}$ compared to $78 \mathrm{~min}$ in external DCR in a comparative study. ${ }^{12}$ Our average time for the procedure is $15-20 \mathrm{~min}$.

The most common complication of endonasal DCR is failure $^{7}$ and the most common cause of failure is scarring at the nasal mucosal and submucosal level ${ }^{10}$ usually in the first 8-9 weeks. ${ }^{13}$ There is considerable inaccuracy when the laser is used to create an ostium, which increases the risk of scarring and granuloma formation especially in children due to an increased fibroblastic response. The inflammatory response may be reduced by the modification of creating a clean nasal mucosal opening. This may be the reason for greater success with surgical compared to laser endonasal DCR. Szubin ${ }^{16}$ attempted a combined procedure with surgically augmented rhinostomy and achieved $97 \%$ success. All patients in Doyle's group had granulation tissue on the first postoperative visit compared to one in our study. ${ }^{17}$ Another patient with previous dacryocystitis developed a mucocele at 6 months requiring excision of the membrane covering the ostium. There were no other early or late complications.

The present data do not support the benefit of one laser from another. Continuous wave lasers $\left(\mathrm{CO}_{2}, \mathrm{KTP}\right.$, $\mathrm{Nd}$ :YAG) have better penetration and provide effective bone removal but are less precise and leave more char ${ }^{11,13}$ which may be the reason for early failure in Doyle's study ${ }^{17}$ Holmium : YAG is a pulsed laser and provides more precise ablation, reducing the risk of peripheral damage to nontarget tissues.

Silicone intubation is usually of no benefit in external $\mathrm{DCR}^{1,2}$ but has been used in endonasal and laser DCR due to the smaller ostium and potential for increased inflammation. Studies where stents were used had better results in endonasal laser DCR..$^{10,11,14,15}$ Four of our patients had stents. An argument against the use of stents is problems during tube removal and requirement of a general anaesthesia. We removed tubes in an outpatient setting. The use of Watzke's sleeve allows an appropriate tension to be maintained keeping the tubes in place while avoiding cheese wiring. Stents are recommended for 3-4 months. Welsh had $89.9 \%$ success with tube retention $>3$ months and $56 \%$ if $<3$ months. ${ }^{18}$ In the study with no success, all tubes were lost by the third week. ${ }^{17}$ We leave the tubes for at least 3 months but some patients had tubes for a longer duration because of failed appointments. The patient who developed a mucocele had tubes removed at 3 months whereas in all others it was present for $>6$ months. This suggests a possible benefit from longer intubation to allow for collagen remodelling. ${ }^{1}$

This article would seem to be the first describing a modified approach for endonasal laser DCR for paediatric patients with simple congenital NLD block, which appears to be encouraging. The study is however limited in being a small series and a larger group is now needed.

\section{Acknowledgements}

Part of this work was presented as a poster at ARVO, April 2004.

\section{References}

1 O'Donnell BA, Adenis JP, Linberg JV, Rose GE, Sullivan TJ, Wobig JL. The failed probing. Clin Exp Ophthalmol 2001; 29: 276-280.

2 Barnes EA, Abou-Rayyah Y, Rose GE. Paediatric dacryocystorhinostomy for nasolacrimal duct obstruction. Ophthalmology 2001; 108(9): 1562-1564.

3 Hakin KN, Sullivan TJ, Sharma A, Welham RAN. Pediatric dacryocystorhinostomy. Aust N Z J Ophthalmol 1994; 22(4): 231-235.

4 Welham RAN, Hughes SM. Lacrimal surgery in children. Am J Ophthalmol 1985; 99: 27-34.

5 Elder MJ. Paediatric dacryocystorhinostomy. Aust N Z J Ophthalmol 1992; 20(4): 333-335.

6 Nowinski TS, Flanagan JC, Mauriello J. Paediatric dacryocystorhinostomy. Arch Ophthalmol 1985; 103: $1226-1228$. 
7 Woog JJ, Kenedy RH, Custer PL, Kaltreider SA, Meyer DR Camara JG. Endonasal dacryocystorhinostomy. A report by the American Academy of Ophthalmology. Ophthalmology 2001; 108: 2369-2377.

8 VanderVeen DK, Jones DT, Tan H, Petersen RA. Endoscopic dacryocystorhinostomy in children. J AAPOS 2001; 5(3): 143-147.

9 Cunningham MJ, Woog JJ. Endonasal endoscopic dacryocystorhinostomy in children. Arch Otolaryngol Head Neck Surg 1998; 124: 328-333.

10 Sadiq SA, Ohrlich S, Jones NS, Downes RN. Endonasal laser dacryocystorhinostomy - medium term results. $\mathrm{Br} \mathrm{J}$ Ophthalmol 1997; 81: 1089-1092.

11 Moore WMH, Bentley CR, Olver JM. Functional and anatomic results after two types of endoscopic endonasal dacryocystorhinostomy. Ophthalmology 2002; 109: 1575-1582.

12 Hartikainen J, Grenman R, Puukka P, Seppa H. Prospective randomized comparison of external dacryocystorhinostomy and endonasal laser dacryocystorhinostomy. Ophthalmology 1998; 105: 1106-1113.

13 Woog JJ, Metson R, Puliafito CA. Holmium : YAG endonasal laser dacryocystorhinostomy. Am J Ophthalmol 1993; 116: 1-10.

14 Boush GA, Lemne BN, Dortzbach RK. Results of endonasal laser assisted dacryocystorhinostomy. Ophthalmology 1994; 105: 955-959.

15 Sadiq SA, Higkulstone CE, Jones NS, Downes RN. Endoscopic Holmium: YAG laser dacryocystorhinostomy. Eye 1996; 10: 43-46.

16 Szubin L, Papageorge A, Sacks E. Endonasal laser assisted dacryocystorhinostomy. Am J Rhinol 1999; 13: 371-374.

17 Doyle A, Russell J, O'Keefe M. Paediatric laser DCR. Acta Ophthalmol Scand 2000; 78: 204-205.

18 Welsh MG, Katowitz JA. Timing of silastic tubing removal after intubation for congenital nasolacrimal duct obstruction. Ophthal Plast Reconstr Surg 1989; 5(1): 43-48. 